\title{
地域高齢者への運動指導における運動定着に寄与する要因の検討
}

\begin{tabular}{|c|c|c|c|c|c|}
\hline 小島 真二 ${ }^{1)}$ & 徳森 & 公彦1) & 坂野 & 紀子 1) & 汪 \\
\hline 久雄 ${ }^{2)}$ & 池田 & 敏 ${ }^{3)}$ & 平田 & 宰久 ${ }^{4)}$ & 岡 \\
\hline 浩平 ${ }^{4)}$ & 荻野 & 景規 ${ }^{1)}$ & & & \\
\hline
\end{tabular}

\section{Factors contributing to enhancement of exercise habituation in exercise intervention for disability prevention in community-dwelling Japanese elderly}

\author{
Shinji Kojima ${ }^{1}$, Kimihiko Tokumori ${ }^{1}$, Noriko Sakano ${ }^{1}$, Da-Hong Wang ${ }^{1}$, Hisao Suzuki ${ }^{2}$, \\ Satoru Ikeda ${ }^{3}$, Tadahisa Hirata ${ }^{4}$, Takashi Oka ${ }^{4}$, Kohei Hara ${ }^{4}$ and Keiki Ogino ${ }^{1}$
}

\begin{abstract}
Recently, resistance training-based exercise programs for the elderly have been widely performed as preventive approaches for long-term care in Japan. Here, we evaluated two health programs in order to find factors that would contribute to the enhancement of exercise habituation in exercise intervention for disability prevention in community-dwelling Japanese elderly. Fifty-two elderly people were instructed to stretch every part of the body and to perform low-intensity resistance training for the lower extremities as basic exercises in two classes. The participants in Class A were instructed once a week for the first four weeks and those in Class B every two weeks for 3 months. At the baseline, and 3 months later, physical performance and body mass index (BMI) were evaluated using a questionnaire survey including information on age, sex, subjective health status, habitual exercise and Self Motivation Test. We examined the factors contributing to exercise habituation by multivariate logistic analysis. There were no significant differences in the results of the questionnaire survey except for mean age between the participants in Class A and Class B. By means of these interventions, the results of Timed Up and Go and the ratio of individuals who regu-
\end{abstract}

1）岡山大学大学院医歯薬学総合研究科公衆衛生学分野 干 700-8558 岡山市鹿田町 2-5-1

2) 岡山大学教育学部 干 700-8530 岡山市津島中 3 丁目 1-1

3) 岡山大学医学部保健学科

干 700-8558 岡山市鹿田町 2-5-1

4）矢掛町健康管理センター

干 714-1201 岡山県小田郡矢掛町矢掛 2977-1 連絡先 小島真二
1. Okayama University, Graduate School of Medicine, Dentistry and Pharmaceutical Sciences, Department of Public Health

2-5-1, Shikata-cho, Okayama 700-8558

2. Okayama University, Faculty of Education 3-1-1, Tsushimanaka, Okayama 700-8530

3. Okayama University Medical School, Faculty of Health Sciences

2-5-1, Shikata-cho, Okayama 700-8558

4. Yakage Town Health Management Center 2977-1 Yakage, Yakage-cho, Okayama-pref. 714-1201 Correspondingauthorskojima@md.okayama-u.ac.jp 
larly exercised were improved, whereas BMI, grip strength and standing on one leg were not. Only $29.4 \%$ of participants followed basic exercises twice a week in Class A, whereas $83.3 \%$ of participants adhered to basic exercises in Class B. Exercise habituation was higher among participants who felt subjectively healthy and habitually exercised, and most of them belonged to Class B, in comparison with subjects who did not exercise habitually. Multivariate analysis indicated that the choice of class and subjective health status of the participants were the most important factors for exercise habituation. Our findings suggest that participant-tailored program planning is important for exercise habituation as an approach to exercise intervention for community-dwelling elderly.

\section{Key words : exercise program, subjective health status, preventive approaches for long-term care}

(Japan J. Phys. Educ. Hlth. Sport Sci. 52: 227-235, March, 2007)

\section{キーワード：運動プログラム, 主観的健康感, 介 護予防}

\section{I 緒言}

近年, 高齢化の進む日本では介護予防の取り組 みが全国で広く行われており（Suzuki et al., 2004), 多くの自治体が転倒予防教室などの介護 予防に関する保健事業を実施している。転倒予防 プログラムに関しては多くの研究がなされ (Gillespie et al., 2003 ; Chang et al., 2004 ; Province et al., 1995), さまざまな知識の普及と ともに筋力トレーニングを主体とした運動指導が 有用とされている。

American College of Sports Medicine (ACSM) （1998）の見解や, Pollock et al. (1994）による 高齢者のレジスタンストレーニングに関する研究 によれば，体力，特に筋力向上を目的とした場合， 週 3 回以上の運動の継続が必要とされる.しかし 住民に広く公平にサービスを提供しなくてはなら ない自治体が，このような保健事業を実施する場 合には, マンパワーの不足は否めない.すなわち, 短期間のプログラムによって，運動を定着させ， 参加者が自宅で運動を継続できるような事業計画 が不可欠である。

疾病予防のために運動をはじめた人の $30-$ $70 \%$ は，6ヶ以内にドロップアウトすると言わ れている (Miller et al., 1997). Franklin et al.
（1988）は，運動からドロップアウトすると予想 される要素を, 喫煙, 体重超過, 意欲の欠如など の personal factor, 強度な運動, 運動のバラエテ イーの欠如などの program factor, パートナーの サポートや天候などの other factorに分類し提示 している、しかしながら, 日本の地域高齢者の場 合, 社会的背景が特有であり, 体力は青年層や壮 年層とは異なるため, 独自の検討が必要となる.

そこでわれわれは, 運動習慣形成への第一歩と して,「出前型」と「中央への出席型」の $2 つ の$ クラスの高齢者の介護予防保健事業を実施し, そ の終了時点で, 指導内容を身につけ, どれだけ実 践しているかを検討することで, 日本の地域在住 高齢者への運動指導における日常生活への運動の 定着に影響を及ぼす要因について検討した。

\section{II 対象と方法}

\section{1. 対象}

平成 17 年 8 月現在, 高齢化率 $30.1 \%$ の岡山県 矢掛町において, 2 つの介護予防保健事業へ参加 した矢掛町在住の 65 歳以上の高齢者 84 名のう ち, 事業開始時と終了時の教室に参加した 52 名 を対象とした。

\section{2. 方法}

1）保健事業としてのプロトコール

2004 年 8 月から 2005 年 5 月に当町では, class 
A とBの 2つの事業を実施した. class A は, 町 の中心から離れた地区の公民館を活用したいわば 「出前型」の事業であり, 地域住民の口コミによ って参加者を募集した。最初に月 4 回集中して実 施し， 3 ケ月後に経過を追うものである。一方, class B は, 町の中心部にある健康管理センター で月 2 回ずつ定期的に 3 ケ月間実施するいわば 「中央への出席型」の事業で公募によって参加者

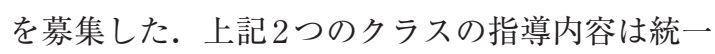
し，ストレッチングと下肢中心の低負荷筋力トレ ーニングを基本体操とし, リズム体操, バランス トレーニングを組み合わせたもので構成した。な お，運動指導については，ACSMの勧める「運 動を持続するための実用的すすめ」を参考として 計画し，運動習慣の定着に努めた。すなわち，指 導スタッフは積極的に参加者へ助言し，さらにク ラスメート同志がサポートしあえるようにクラス の雲囲気作りに留意しクラスを運営した。また， 指導する運動強度は過負荷にならないように設定 し，コーディネーションを意識したゲームなどリ クリエーションの意味合いも取り入れた。高齢者 を対象とすることから安全への配慮を重視し, 約 20 名のクラスでの集団的な運動指導に対して, 医師, 保健師, 理学療法士といった医療従事者を 毎回 4 名程度配置した。

2) 基本体操

今回提供した基本体操は, 6 種類のストレッチ ングと 3 種類の自重負荷による筋力トレーニング からなっている。6 種類のストレッチングでは, （a）腰と臀部，（b）横腹，（c）大腿前面，（d） 大腿後面，(e) 肩，(f) 下腿後面（下腿三頭筋） をそれぞれ 20 - 30 秒間ゆっくりと実施した。 ま た， 3 種類の筋力トレーニングは，(a) 椅子に座 って膝伸展位での足関節の背屈・底曲, (b) 力 ーフレイズ，（c）ハーフスクワットをそれぞれ， 10 回 1 セットで実施した。低負荷でより効果を期 待するために石井（2005）が示すように，いずれ の動作も, 約 3 秒間のゆっくりとした連続した動 作で実施し, 各屈曲伸展の間のインターバルは取 らずに繰り返し行った。

\section{3) 評価}

開始時には, 主観的健康感, 運動習慣, 運動量 増加の意欲, 慢性疾患の有無さらにSelf-Motivation Test（以下「SMT」と略す）について自記 式質問票によって調査し, 同時にBody Mass Index（以下「BMI」と略す）や体力を測定した。 各項目は以下のように分類し, 得点化した。

主観的健康感は，「健康である（1点)」「それ 以外 $(0$ 点 $) 」 に$ 分類した。運動習慣は, 健康日 本 21 の定義に基づき, 週 2 回以上, 30 分/日以上 の運動を 1 年以上継続されていることを「運動習 慣あり」と定義した。「運動習慣あり（1点）」に 該当しないものを,「運動しない $(0$ 点 $) 」 に$ 分類 した，運動量増加の意欲は，「あり（1点）」「な い（0 点)」から選択させた。慢性疾患の有無に 関しては，かかりつけの主治医がおり定期的に受 診しているかによって，「慢性疾患あり（1点）」 「慢性疾患なし（0点）」に分類した。セルフモチ ベーションテストは, Dishman et al. (1980) が 開発した運動コンプライアンスへの可能性を評価 する方法であり，これに準拠しアンケートを実施 した。体力およびActivity of daily life (ADL) の評価としては, 筋力の指標として握力, 静的バ ランスの指標として開眼片足立ちテストおよび動 的バランスの指標として介護予防領域で広く用い られている Podsiadlo et al. (1991) が示した Timed up \& Go（以下「TUG」と略す）を用い た。

また，3ケ月の事業終了時点では，われわれが 提供した基本体操を自宅でどれくらい実施してい るかなど, 運動実施状況に関するアンケートのほ か, BMI, TUG, 握力および開眼片足立ちテス トを測定した。基本体操の実施状況については, 「週 2-3 回以上運動している（1点）」「それ以下 (0 点)」と分類した。なお, この時点で週 2 回以 上 30 分/回以上の運動をしている者を「運動定着 者」と定義した。

\section{3) 統計解析方法}

クラス別の参加者の属性および運動指導前後で の運動実施状況の調査, TUG, 握力, 開眼片足 立ちテストの結果について, $\mathrm{t}$-検定, $\chi^{2}$ 検定お 
よびFisherの直接確率計算法によって比較した。

さらに運動定着にかかわる要因を検討するた め, 52 名の参加者を, 基本体操を週 2 回以上実施 した定着群とそれ以外の非定着群に分け, それぞ れの要因について2 群を比較した。また, 運動定 着に寄与する要因を検討するために, 今回運動指 導を行った指導内容の自宅での実施状況を従属変 数とし, 事業開始時の年齢, 性別, BMI, 主観的 健康感, 運動習慣, 運動量増加の意欲, SMT, 慢性疾患の有無, 参加したプログラムを説明変数 とした，ステップワイズ法による多変量ロジステ イック解析を行った. なお, 統計解析には, 統計 解析ソフト SPSS ver.12.0Jを用い, 有意水準は 5\%とした。
4）インフォームドコンセント

この調査は, 岡山大学疫学調査倫理委員会の承 認を得た上，参加者の同意を得て実施した。

\section{III 結果}

\section{2 つのクラスの概要と参加者の基本属性} (Table 1)

クラス別の参加者の属性については, class A の方が参加者の平均年齢は高かったが, 性別, 主 観的健康感, SMT, 運動習慣増加の意欲につい ては，偏りがなかった。

クラス別に参加者の運動習慣を見ると, 開始時 には, class Aの参加者の $35.3 \%$ が運動習慣者で

Table 1 Characteristics of two health care services

\begin{tabular}{|c|c|c|}
\hline & Class A & Class B \\
\hline \multicolumn{3}{|l|}{ Summary of the class } \\
\hline No.of participants & $\mathrm{n}=34$ & $\mathrm{n}=18$ \\
\hline Method of recruiting & by word of mouth & public recruitment \\
\hline Place & public hall in each district & $\begin{array}{l}\text { health management center } \\
\text { in the center of this town }\end{array}$ \\
\hline Protocol & once a week for 1 month & twice a month for 3 months \\
\hline \multicolumn{3}{|c|}{ Property of participants (at the beginning) } \\
\hline \multirow[t]{2}{*}{ Age } & $74.4 \pm 5.75 \dagger$ & $70.3 \pm 4.50 \dagger$ \\
\hline & \multicolumn{2}{|c|}{$\mathrm{P}<0.05 * *$} \\
\hline \multicolumn{3}{|l|}{ Sex } \\
\hline male & $10(29.4 \%)$ & 2(11.1\%) \\
\hline \multirow[t]{2}{*}{ female } & $24(70.6 \%)$ & $16(88.9 \%)$ \\
\hline & \multicolumn{2}{|c|}{ n.s. $*$} \\
\hline \multicolumn{3}{|l|}{ Subjective Health Status（SHS） } \\
\hline healthy & $25(73.5 \%)$ & $14(77.8 \%)$ \\
\hline \multirow[t]{2}{*}{ unwell } & $9(26.5 \%)$ & $4(22.2 \%)$ \\
\hline & \multicolumn{2}{|c|}{ n.s. $*$} \\
\hline \multirow[t]{2}{*}{ Self Motivation Test（SMT） } & $23.5 \pm 3.78 \dagger$ & $24.6 \pm 4.94 \dagger$ \\
\hline & \multicolumn{2}{|c|}{ n.s. ${ }^{* *}$} \\
\hline \multicolumn{3}{|l|}{ Exercise habit } \\
\hline with exercise habit & $12(35.3 \%)$ & $11(61.1 \%)$ \\
\hline \multirow[t]{2}{*}{ without exercise habit } & $22(64.7 \%)$ & $7(38.9 \%)$ \\
\hline & \multicolumn{2}{|c|}{ n.s. $*$} \\
\hline \multicolumn{3}{|c|}{ Motivation for increasing exercise } \\
\hline Yes & $25(73.5 \%)$ & $17(94.4 \%)$ \\
\hline \multirow[t]{2}{*}{ No } & $9(26.5 \%)$ & $1(5.6 \%)$ \\
\hline & \multicolumn{2}{|c|}{ n.s. $*$} \\
\hline
\end{tabular}

$\dagger:$ mean $\pm \mathrm{SD} *$ : Fisher's exact probability test, ${ }^{* *}$ : paired t-test 


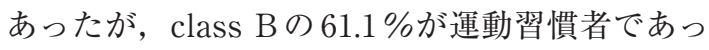
た。

\section{2. この保健事業による運動指導の成果} (Table 2)

運動習慣については, 保健事業開始時には 44\%であった運動習慣者が，終了時には $57.7 \%$ となっており増加傾向が見られた。 またクラス別 にみると, class A では 44.1\%, class B では $83.3 \%$ 人に運動が定着していた。すなわち，今 回の事業を契機に運動定着者の割合は, class A では+ $9.1 \%$, class Bでは $+22.2 \%$ の増加をみた.

今回指導した内容である基本体操の実施状況 は, class A では, 週 2 回以上実施しているもの は，29.4\%に過ぎなかった。一方， class Bでは， $83.3 \%$ 淍 2 回以上実施していた。

体力面での成果としては, 開始時に比べ 3 カ月 後ではTUGは改善していた。しかしながら，開 眼片足立ちテストでは変化が見られず，筋力に関 してはむしろ低下していた，男女別で見ると， TUGは女性で顕著に改善しているにもかかわら ず男性では統計学的に有意な改善は見られなかっ た。また，主観的健康感と TUGの関係について
は，主観的健康感と TUGには有意な違いは見ら れなかったが（独立 2 群の $\mathrm{t}$-検定, $\mathrm{p}=0.195$ ), 主観的に健康感のあるものは, 運動の成果として, 3 カ月後には TUGの改善を認めていた.

\section{3. 多変量ロジスティック解析による運動定着 に寄与する要因の検討}

今回指導した基本体操を週 2 回以上実施した人 を定着群，それより少ない人を非定着群として， 52 名の参加者を 2 群に分け，比較した（Table 3). 定着群と非定着群では，それぞれの群に含まれる 参加者の年齢, 性別, SMT, BMI, 慢性疾患の 有無, 運動量増加の意欲には偏りがなかった。し かしながら主観的健康感については，健康感のあ る人の方が，定着群に多く含まれていた，運動習 慣に関しても，定着群には，事業開始時点で運動 習慣があると回答した人が多く含まれていた。さ らに, 定着群にはclass Bへの参加者が多く, 非 定着群にはclass Aへの参加者が多かった。

運動定着に影響を及ぼす要因を検討することを 目的としたステップワイズ法による多変量ロジス ティック解析の結果を Table 4 に示す. 今回検討 に用いた項目のうち，運動定着に影響を及ぼして

Table 2 Change of the reusult before and after the health services

\begin{tabular}{|c|c|c|c|}
\hline & at the beginning & after 3 months & P-value \\
\hline BMI $\left(\mathrm{kg} / \mathrm{m}^{2}\right) \quad(\mathrm{n}=52)$ & $23.2 \pm 2.95$ & $23.6 \pm 2.98$ & $0.002^{*}$ \\
\hline male $(\mathrm{n}=12)$ & $22.4 \pm 2.98$ & $23.0 \pm 2.74$ & $0.003 *$ \\
\hline female $(n=40)$ & $23.5 \pm 2.94$ & $23.7 \pm 3.06$ & $0.040 *$ \\
\hline Grip strength $(\mathrm{kg}) \quad(\mathrm{n}=52)$ & $24.6 \pm 7.36$ & $23.5 \pm 6.96$ & $0.002^{*}$ \\
\hline male $(\mathrm{n}=12)$ & $33.6 \pm 7.08$ & $31.6 \pm 7.53$ & $0.049 *$ \\
\hline female $(n=40)$ & $21.9 \pm 4.91$ & $21.0 \pm 4.60$ & $0.019^{*}$ \\
\hline Standing on one leg $(\mathrm{sec}) \quad(\mathrm{n}=52)$ & $40.4 \pm 38.8$ & $37.2 \pm 34.3$ & $0.428 *$ \\
\hline male $(\mathrm{n}=12)$ & $42.5 \pm 37.4$ & $48.5 \pm 44.4$ & $0.628 *$ \\
\hline female $(\mathrm{n}=40)$ & $39.8 \pm 39.7$ & $33.9 \pm 30.5$ & $0.125^{*}$ \\
\hline TUG (sec) $\quad(n=52)$ & $9.29 \pm 4.76$ & $8.07 \pm 20.7$ & $<0.001^{*}$ \\
\hline male $(\mathrm{n}=12)$ & $9.25 \pm 7.57$ & $8.88 \pm 8.68$ & $0.349^{*}$ \\
\hline female $(n=40)$ & $9.30 \pm 3.66$ & $7.83 \pm 2.75$ & $<0.001^{*}$ \\
\hline healthy (SHS) $(\mathrm{n}=39)$ & $8.79 \pm 3.75$ & $7.37 \pm 2.66$ & $<0.001^{*}$ \\
\hline unwell (SHS) $(\mathrm{n}=13)$ & $10.8 \pm 6.96$ & $10.2 \pm 8.09$ & 0.169 \\
\hline \multicolumn{4}{|l|}{ Exercise Habit $(\mathrm{n}=52)$} \\
\hline No. of participants with exercise habit $(\mathrm{n}=12)$ & $23(44.2 \%)$ & $30(57.7 \%)$ & \multirow{2}{*}{$0.17 * *$} \\
\hline No. of participants without exercise habit $(\mathrm{n}=40)$ & $29(55.8 \%)$ & $22(42.3 \%)$ & \\
\hline
\end{tabular}

Data are expressed by mean \pm standad deviation. ${ }^{*}$ : paired t-test, ${ }^{* *}$ : chi-square test 
Table 3 Comparison between adherence group and non-adherence group

\begin{tabular}{|c|c|c|}
\hline & Adherence group & Non-adherence group \\
\hline No. of participants & 25 & 27 \\
\hline \multirow[t]{2}{*}{ Age } & $72.6 \pm \underbrace{5.92 \dagger}$ & $73.3 \pm 5.50 \dagger$ \\
\hline & \multicolumn{2}{|c|}{ n.s. $* *$} \\
\hline \multicolumn{3}{|l|}{ Sex } \\
\hline male & $5(20.0 \%)$ & $7(25.9 \%)$ \\
\hline \multirow[t]{2}{*}{ female } & $20(80.0 \%)$ & $20(74.1 \%)$ \\
\hline & \multicolumn{2}{|c|}{ n.s. * } \\
\hline \multirow[t]{2}{*}{ BMI } & $23.5 \pm 2.89 \dagger$ & $22.9 \pm 3.04 \dagger$ \\
\hline & \multicolumn{2}{|c|}{ n.s. $* *$} \\
\hline \multicolumn{3}{|l|}{ Chronic disease } \\
\hline Yes & $17(68.0 \%)$ & $19(70.4 \%)$ \\
\hline \multirow[t]{2}{*}{ No } & $8(32.0 \%)$ & $8(29.6 \%)$ \\
\hline & \multicolumn{2}{|c|}{ n.s. $*$} \\
\hline \multicolumn{3}{|l|}{ Subjective health status } \\
\hline healthy & $22(88.0 \%)$ & $17(63.0 \%)$ \\
\hline \multirow[t]{2}{*}{ unwell } & $3(12.0 \%)$ & $10(37.0 \%)$ \\
\hline & \multicolumn{2}{|c|}{$\mathrm{p}<0.05^{*}$} \\
\hline \multirow{4}{*}{$\begin{array}{l}\text { Exercise habit } \\
\text { with exercise habit } \\
\text { without exercise habit }\end{array}$} & & \\
\hline & $15(60.0 \%)$ & $8(29.6 \%)$ \\
\hline & $10(40.0 \%)$ & $19(70.4 \%)$ \\
\hline & \multicolumn{2}{|c|}{$\mathrm{p}<0.05^{*}$} \\
\hline \multicolumn{3}{|c|}{ Motivation for increasing exercise } \\
\hline Yes & $22(88.0 \%)$ & $20(74.1 \%)$ \\
\hline \multirow[t]{2}{*}{ No } & $3(12.0 \%)$ & $7(25.9 \%)$ \\
\hline & \multicolumn{2}{|c|}{ n.s. $* * *$} \\
\hline \multirow[t]{2}{*}{ SMT } & $24.6 \pm 4.78 \dagger$ & $23.2 \pm 3.54 \dagger$ \\
\hline & \multicolumn{2}{|c|}{ n.s. ${ }^{*}$} \\
\hline \multicolumn{3}{|l|}{ Class } \\
\hline Class A & $10(40.0 \%)$ & $24(88.9 \%)$ \\
\hline \multirow[t]{2}{*}{ Class B } & $15(60.0 \%)$ & $3(11.1 \%)$ \\
\hline & \multicolumn{2}{|c|}{ p < $<0.05^{*}$} \\
\hline
\end{tabular}

$\dagger:$ Mean $\pm \mathrm{SD}, *$ : chi-square test, $* *$ : t-test, $* * *$ : Fisher's exact probability test

いた要因は，参加したクラスの違いと主観的健康 感のみであった。

\section{IV 考察}

Van der Bij et al. (2002) の総説によれば，高 齢者にとって，運動はさまざまな利益をもたらす ので, 運動をはじめることや運動量を維持するた めに有効な運動介入の研究が望まれている.われ
われは, 高齢化率が高く, 介護予防が重要な課題 である岡山県矢掛町で, 高齢者に対する運動指導 を中心とした2つの保健事業を実施した。2つク ラスの参加者とも, 主観的健康感が高く, 健康に 関心を持つ人が保健事業の呼びかけに応じて多く 参加されたものと思われた。また，出前型のクラ スには開催場所が自宅から近いこともあってより 高齢の方が多く参加した。

運動指導の成果については, 今回提供した週 1 
Table 4 Factors related with exercise adherence by multivariate analysis

\begin{tabular}{lcc}
\hline \multicolumn{1}{c}{ Variable } & Odds Ratio & p-value \\
\hline Constant & 0.005 & 0.001 \\
Class & 16.364 & 0.001 \\
Subjective Health Status & 7.118 & 0.039 \\
Age & - & 0.120 \\
Sex & - & 0.586 \\
Exercise habit & - & 0.205 \\
Motivation for & - & 0.945 \\
increasing exercise & - & 0.312 \\
SMT & - & 0.533 \\
BMI & - & 0.312 \\
Chronic disease & &
\end{tabular}

Cox\&Snell R2: 0.319, NagelKerke R2: 0.426

回1ヶ月集中して行った class A も，2週間に1度 ずつ定期的に実施した class B も，3ケ月後には， この事業を契機として運動定着者の割合は増加し ていることから, 双方ともに運動習慣の定着には 役立つものと考えられた。高齢者が対象であり運 動強度の高いものを避けたこともあって，この 3 ヶ月間では，運動量の増加に伴う BMIの低下ゃ 握力や開眼片足立ちの向上は見られなかった。し かしながら，TUGの改善が見られたことから， 介護予防の観点では有効な保健事業ができたもの と思われた。とくに参加者に女性が多いことや女 性でTUGは有意に改善をしたことから，女性に 対して効果的な保健事業計画であった可能性が示 唆された，在宅高齢者の運動指導には，女性の方 が男性に比べて関心があるものと考えられた。

次に, 今回の多変量解析の結果から, 高龃者の 運動定着に影響を及ぼす要因は，参加したクラス の違いと主観的健康感であることが示された。

クラスの違いについては, class Bに参加した ことが運動定着につながったことを示している.

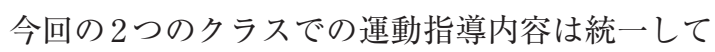
いたことから，日程，時間，場所や募集方法とい った事業計画が影響した可能性がある。さらに, class Bはclass Aに比べて, 参加者の平均年齢が 若いことから, 各参加者の属性によって構成され るクラス全体の䨌囲気や, クラスメートによるサ ポートといった要因も，影響を及ぼした可能性が
うかがえた。

主観的健康感に関しては, SMTよりも運動定 着に影響を及ぼしたことは非常に興味深い。運動 定着に関する参加者の要因としては, McGee H et al.（1992）は，男性に比べて女性の方が定期 的な運動からドロップアウトする傾向が高いこと を示し, Sotile WM et al. (1998) は, 若年者よ り高齢者の方がプログラムに参加しやすいと述べ ているが, 今回の多変量解析では, 年齢, 性別, BMI S SMT は運動定着に影響を及ぼさなかっ た.今回の参加者においては, 主観的健康感と TUGの結果には関連がなかったことから, 主観 的健康感は体力や ADLのレベルとは独立してお り, 健康であるという自覚が, 高齢者にとって健 康のために運動を続ける大きな要因となっている ことが示唆された。中村ほか（2002）によれば, 社会活動参加が高齢者の主観的健康感を向上・保 持させる可能性が示されている. したがって，参 加者の運動の定着を高めるには, 社会活動参加に 導くようなサポートすなわち適切な情報の提供な どによって主観的健康感を高めるような工夫が望 まれる．またこのような保健事業自体が積極的に 参加できる社会活動の場といえるようなクラスの 雲囲気作りが重要であると考えられる。

以上のことから, 効果的な地域高齢者への運動 指導を行うためには, 無理のない運動強度の設定 や運動種目を選択するだけでなく, 主観的健康感 や, 性別や年齢構成, 体力や ADLのレベルなど 参加者の背景を踏まえて, 参加者が喜んで参加で きる場を提供できるプログラムを, 開催日程, 時 間, 場所や募集方法などに留意しながら計画する ことが望まれる。また，スタッフからの助言や対 話による積極的なサポートによって，プログラム に参加することで健康感が高まるように運営する ことが大切であると考えられた。

今後, 日本では介護保険制度の改革によって介 護予防が重視されるため, 家族やかかりつけ医や ケアマネージャーといった他者からの勧めによっ て介護予防プログラムに参加する人が増えると思 われる.すなわち, 積極的な運動プログラムへの 参加の意思を持たない高齢者の運動教室への参加 
者が増える可能性が否めない. プログラムの運営 にあたっては, 参加者全体のモチベーションの維 持は重要な課題となることが予想され, 適切にプ ログラムを計画することが望まれる。

本研究の限界としては, 対象者が高齢者であり, 質問内容を限定せざるを得なかったため，今回の 検討でとりあげていない要因が, 運動定着に影響 を及ぼす可能性は否定できない.さらに, 本研究 は介入研究であるが, 当町の保健事業として実施 したため, 参加者を無作為に募集したわけではな い.したがって, 今回の参加者は, 健康への関心 が高い対象者が集まった可能性もあり，検討課題 を残している。

\section{V ま と め}

地域高齢者への介護予防事業では，参加者の日 常生活の中に運動が定着し継続することが大切で ある. 今回の検討では, 運動指導内容の定着には, クラスのもつ特徵と参加者の主観的健康感が影響 を及ぼす要因として指摘された。したがって，ク ラスの特徵はクラス運営の計画やスタッフの指導 内容さらには参加者の属性によって形成されるた め, 参加者の属性にも配慮した保健事業の構築が 望まれ, 一方, 教室運営には主観的健康感を高め るようなサポートとしてスタッフの助言や対話さ らには適切な情報の提供などが重要である.

\section{謝 辞}

岡山大学との共同研究に多大なご理解とご支援 を頂いています山岡治喜前矢掛町長, 山野通彦矢 掛町長をはじめ, 矢掛町職員の皆様, 老人クラブ の皆様に，心より御礼申し上げます。また，矢掛 町と岡山大学の連携の基盤を築いてくださった， 岡山大学教授・吉良尚平先生（故人）に深く御礼 申し上げ，ご冥福をお祈りいたします。

\section{文献}

American College of Sports Medicine Position Stand (1998) The recommended quantity and quality of exercise for developing and maintaining cardiores- piratory and muscular fitness, and flexibility in healthy adults. Med. Sci. Sports. Exerc., 30: 975991.

Chang, J.T., Morton, S.C., Rubenstein, L.Z., Mojica, W.A., Maglione, M., Suttorp, M.J., Roth. E.A., and Shekelle, P.G. (2004) Interventions for the prevention of falls in older adults: systematic review and meta-analysis of randomised clinical trials. BMJ, 328: $680-686$.

Dishman, R.K., Ickes, W., and Morgan, W.P. (1980) Self-motivation and adherence to habitual physical activity. J. Appl. Social. Psychol., 10: 115-132.

Franklin, B.A. (1988) Program factors that influence exercise adherence: practical adherence skills for clinical staff. In: Dishman, R. (Ed) Exercise adherence: its impact on public health. Human Kinetics: Campaign, pp. 237-258.

Franklin, B.A., Whaley, M.H., and Howley, E.T. (Eds) (2000) ACSM's guidelines for exercise testing and prescription sixth edition. American College of Sports Medicine. Lippincott Williams \& Wilkins: Philadelphia, Pennsylvania, pp. 245-257.

Gillespie, L.D., Gillespie, W.J., Robertson, M.C., Lamb, S.E., and Cumming, R.G., Rowe, B.H. (2003) Interventions for preventing falls in elderly people. Cochrane Database Syst. Rev. 4.

石井直方（2005）低負荷レジスタンストレーニング の理論と応用 加圧トレーニングとノンロックス ロー法を中心に。日本臨床スポーツ医学会誌, 13 (4) : 56.

McGee, H. and Horgan, J. (1992) Cardiac rehabilitation programmes: are women less likely to attend? BMJ, 305: 283-284.

Miller, N.H. (1997) Compliance with treatment regimens in chronic asymptmatic disease. Am. J. Med., 102: 43-49.

中村好一 - 金子 勇 - 河村優子 - 坂野達郎 - 内藤佳 津雄 - 前田一男 - 黒部睦夫 - 平田 滋 - 矢崎俊 樹・後藤康彰・橋本修二 (2002) 在宅高齢者の主 観的健康感と関連する因子. 日本公衛誌，49： 409-416.

Podsiadlo, D. and Richardson, S. (1991) The timed "Up and Go" a test of basic functional mobility for frail elderly persons. J. Am. Geriatr. Soc., 39: 142- 
148.

Pollock, M.L., Graves, J.E., Swart, D.L., and Lowenthal D.T. (1994) Exercise training and prescription for the elderly. South. Med. J., 87: 88-95.

Province, M.A., Hadley, E.C., Hornbrook, M.C., Lipsitz, L.A., Miller, J.P., Mulrow, C.D., Ory, M.G., Sattin, R.W., Tinetti, M.E., and Wolf, S.L. (1995) The effects of exercise on falls in elderly patients. A preplanned meta-analysis of the FICSIT Trials. JAMA, 273: 1341-1347.

Sotile, W.M. and Miller, H.S. (1998) Helping older patients to cope with cardiac and pulmonary disease.
J. Cardiopulm. Rehabil., 18: 124-128.

Suzuki, T., Kim, H., Yoshida, H., and Ishizaki, T. (2004) Randomized controlled trial of exercise intervention for the prevention of falls in communitydwelling elderly Japanese women. J. Bone. Miner. Metab., 22: 602-611.

Van der Bij, A.K., Laurant, M.G., and Wensing, M. (2002) Effectiveness of physical activity interventions for older adults: a review. Am. J. Prev. Med., 22: $120-133$.

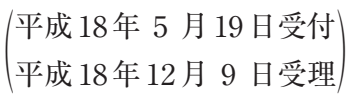

